\title{
Immobilized $\beta$-galactosidase onto magnetic particles coated with polyaniline: Support characterization and galactooligosaccharides production
}

\author{
David F.M. Neri ${ }^{\mathrm{a}, \mathrm{b}, *}$, Victor M. Balcão ${ }^{\mathrm{a}, \mathrm{c}}$, Fernando O.Q. Dourado ${ }^{\mathrm{a}}$, José M.B. Oliveirad ${ }^{\mathrm{d}}$, \\ Luiz B. Carvalho Jr. ${ }^{b}$, José A. Teixeira ${ }^{a}$ \\ a IBB-Institute for Biotechnology and Bioengineering, Centre of Biological Engineering, Universidade do Minho, Campus de Gualtar, P-4710-057 Braga, Portugal \\ ${ }^{\mathrm{b}}$ Departamento de Bioquímica and Laboratório de Imunopatologia Keizo Asami, Universidade Federal de Pernambuco, Brazil \\ ' GIBQB-Grupo de Investigação em Bioengenharia e Química Biofarmacêutica, Universidade Fernando Pessoa, Rua Carlos da Maia ${ }^{\circ}$ 296, P-4200-150 Porto, Portugal \\ d Instituto de Física dos Materiais da Universidade do Porto, Porto, Portugal
}

\section{A R T I C L E I N F O}

\section{Article history:}

Received 7 April 2010

Received in revised form 2 February 2011

Accepted 4 February 2011

Available online 4 March 2011

\section{Keywords:}

Covalent immobilization

$\beta$-Galactosidase

Aspergillus oryzae

Galacto-oligosaccharides

Magnetic support

Polyaniline

\begin{abstract}
A B S T R A C T
Magnetite particles $(<100 \mu \mathrm{m})$ obtained by coprecipitation of $\mathrm{Fe}^{2+}$ and $\mathrm{Fe}^{3+}$ and coated with polyaniline (MAG-PANI) were used to immobilize Aspergillus oryzae $\beta$-galactosidase via glutaraldehyde. The amount of $\beta$-galactosidase immobilized onto MAG-PANI was ca. $2.04 \mathrm{mg} / \mathrm{g}$ support. This magnetic enzymatic derivative was capable to act on lactose and to produce tri and tetragalactosides (transgalactosylation) and the catalytic properties were similar to the soluble enzyme. For lactose concentrations up to $100 \mathrm{~g} / \mathrm{L}$, no differences were observed in the enzyme specific activity between free and immobilized forms $(100 \%$ of specific activity retention), but for higher lactose concentrations the initial specific reaction rate of the immobilized form was affected by increasing lactose concentrations. The Activation Energy values for both free and immobilized forms were similar, around $16 \pm 1.4 \mathrm{KJ} / \mathrm{mol}$. The tri and tetra-galactosides production by both soluble and immobilized enzyme was not affected by temperature in the range of $30-60{ }^{\circ} \mathrm{C}$. As the initial lactose concentration increased from $5 \%$ to $50 \%$, the maximum GOS content in the product increased from $11.2 \%$ (at $35 \%$ conversion) to $26.1 \%$ (at $56 \%$ conversion) for the free enzyme and from $10.8 \%$ (at $33 \%$ conversion) to $26.0 \%$ (at $52 \%$ conversion) for the immobilized enzyme. The MAGPANI was characterized by X-ray diffraction, Fourier transform infrared spectroscopy, elemental analyzer, scanning electronic microscope, differential scanning calorimeter, thermogravimetric analyzer, vibrating sample magnetometer and thermomagnetization. These analysis showed rhombohedra particles presenting good magnetic response, evidences for the PANI coating and protein immobilization and magnetite as the predominant component. This magnetic $\beta$-galactosidase derivative presents the following advantages: simple synthesis using low cost reagents, catalytic properties similar to the soluble enzyme and easy removal from the reaction mixture by a magnetic field and reuse.
\end{abstract}

(c) 2011 Elsevier B.V. All rights reserved.

\section{Introduction}

$\beta$-Galactosidase (EC:3.2.1.23) has been a popular enzyme for its hydrolytic action on lactose. The transferase activity has also attracted the attention of researchers because the produced oligosaccharides have a beneficial effect on the growth of desirable intestinal microflora. Moreover, the transferase reaction can be used to attach galactose to other chemicals and consequently have potential application in the production of food ingredients, pharmaceuticals and other biological active compounds [1].

\footnotetext{
* Corresponding author at: Universidade Federal do Vale do São Francisco - UNIVASF. Avenida José de Sá Maniçoba, S/N, Cx. Postal 252, CEP.: 56.304-205, Centro, Petrolina - PE, Brazil. Tel.: +55 8738629354.

E-mail addresses: davidfmneri@yahoo.com.br (D.F.M. Neri), lbcj@hotlink.com.br (L.B. Carvalho Jr.), jateixeira@deb.uminho.pt (J.A. Teixeira).
}

Oligosaccharides formation is controlled by the ratio of transferase and hydrolase activities of the enzyme and this depends on the enzyme source, the concentration and nature of the substrate and the reaction conditions ( $\mathrm{pH}$, temperature and time) [2-4]. High lactose concentration, elevated temperature and lower water activity [2] favor the transgalactosylation in relation to hydrolysis. A detailed description of the GOS synthesis process together with a model characterizing the different reaction steps was described by Neri et al. [5].

Although hydrolysis of synthesised oligosaccharides competes with transgalactosylation, the latter can be favoured at high lactose concentration, elevated temperature and lower water activity [2].

Magnetic supports have been utilized for different immobilized enzymes [5-9]. The advantages of small magnetic particles for enzyme immobilization in bioprocesses are: improvement of the mass-transfer properties of immobilized enzymes suspended in a viscous solution, in which the promotion of mass transfer by agita- 
tion is difficult [6]; reuse and easy separated from reaction medium by applying a magnetic field [10] and reduction of the capital and operation costs [11].

A magnetic $\beta$-galactosidase composite has been prepared using magnetite functionalized by treatment with polyethyleneimine and crosslinked with glutaraldehyde [12]. The aminated magnetic poly(glycidyl methacrylate-co-methylmethacrylate) beads were used for the covalent immobilization of $\beta$-galactosidase from Escherichia coli via glutaric dialdehyde activation [13]. $\beta$-Galactosidase from Kluyveromyces lactis was covalently immobilized onto a polysiloxane-polyvinyl alcohol magnetic (mPOS-PVA) composite, using glutaraldehyde as activating agent [14].

A tremendous amount of research has been carried out in the field of conducting polymers since 1977 as has been recognized by the 2000 Nobel Prize in Chemistry awarded to Alan J. Heeger, Alan G. MacDiarmid and Hideki Shirakawa. Polyaniline (PANI) is also unique among conducting polymers as it has a very simple acid/base doping/dedoping chemistry [15]. The organic metal PANI is one of the most widely used conducting polymers and can be used neat or as blends and in compounds with commodity polymers, such as polyethylene, polypropylene, polystyrene, soft PVC, poly-(methylmetacrylate), phenol-formaldehyde resins, melamineformaldehyde resins, epoxies, thermoplastic elastomers and polysiloxane. PANI has been used as a coating of different materials for immobilization of biomolecules [16-19].

The advantages of using a polymer bed onto which the enzyme was immobilized, relative to using a standard support with amine groups, lies in the fact that polymeric molecules attached onto the support surface acts like a soft bed in a non-distorting fashion, preventing the enzyme molecules from opening too much. This clearly results in a higher activity of the immobilized enzyme [20,21].

In the present work magnetite (MAG) was coated with PANI, activated with glutaraldehyde and Aspergillus oryzae $\beta$-galactosidase was covalently immobilized for galactooligosaccharides production. The catalytic properties of the enzymatic derivative were investigated. Furthermore, MAG-PANI was characterized by Fourier transform infrared spectroscopy (FTIR), elemental analysis, X-ray diffraction (XRD), thermogravimetric analysis (TGA), differential scanning calorimetry (DSC), vibrating sample magnetometer (VSD), scanning electron microscopy (SEM) and thermomagnetization.

\section{Experimental}

\subsection{Magnetite synthesis and polyaniline coating}

MAG support was prepared by the coprecipitation method, by adding $\mathrm{NH}_{4} \mathrm{OH}$ into a mixed solution containing $0.6 \mathrm{M} \mathrm{FeCl}_{2}$ and $1.1 \mathrm{M} \mathrm{FeCl}_{3}(1: 1)$ until obtaining $\mathrm{pH} 11.0$, for $30 \mathrm{~min}$ at $100^{\circ} \mathrm{C}$. MAG particles were thoroughly washed with deionized water until $\mathrm{pH} 7.0$, dried at $105^{\circ} \mathrm{C}$ overnight and finally sieved $(<100 \mu \mathrm{m})$. The MAG particles were treated with $0.1 \mathrm{M} \mathrm{KMnO}_{4}$ solution at $50^{\circ} \mathrm{C}$ overnight, washed with distilled water and immersed into $0.5 \mathrm{M}$ aniline solution prepared in $1.0 \mathrm{M} \mathrm{HNO}_{3}$. Polymerization was allowed to occur for $2 \mathrm{~h}$ and after that the MAG-PANI were successively washed with distilled water, $0.1 \mathrm{M}$ citric acid and distilled water.

\section{2. $\beta$-Galactosidase immobilization}

MAG-PANI particles (100 mg) were treated with $2.5 \% \mathrm{w} / \mathrm{v}$ glutaraldehyde $(1 \mathrm{~mL})$ and $20 \mathrm{mM}$ citrate-phosphate buffer, $\mathrm{pH} 4.5$ $(9 \mathrm{~mL})$ for $2 \mathrm{~h}$ under stirring at $25^{\circ} \mathrm{C}$. Activated MAG-PANI were washed with distilled water 10 times and incubated overnight with $10 \mathrm{~mL}$ of $\beta$-galactosidase ( $4 \mathrm{mg}$ solid $/ \mathrm{mL}$ ) from A. oryzae
(SIGMA, Japan). The enzyme derivative was boiled in the presence of $\beta$-mercaptoethanol and SDS, followed by electrophoresis of the supernatant. No subunits could be found, implying that full structural stabilization had been achieved. Also, as verified experimentally, the fact that the immobilized enzyme retained its full activity following immobilization is per se evidence that functional stabilization had also been achieved.

\section{3. $\beta$-Galactosidase activity, protein and activation energy determinations}

One $\beta$-galactosidase unit (U) was defined as the amount of enzyme which liberated $1 \mu \mathrm{mol}$ of glucose per min at $40^{\circ} \mathrm{C}$ and $\mathrm{pH}$ 4.5. The initial $\beta$-galactosidase activity was measured for all the initial lactose concentrations assayed (from $50 \mathrm{~g} / \mathrm{L}$ to $500 \mathrm{~g} / \mathrm{L}$ ) by quantifying the variation of glucose concentration with time during the first $10 \mathrm{~min}$ of reaction. The product released in the assay, glucose, was determined by high performance liquid chromatography HPLC analysis using a RI detector. The protein concentration was determined according to the method described by Smith et al. [22] using bovine serum albumin as standard. The amount of immobilized protein was calculated by the difference between the amount of protein offered to the support for immobilization and that found in the supernatant and the washing buffers.

The activation energies $\left(E_{\mathrm{a}}\right)$ for both soluble and immobilized enzyme derivative were calculated according to the Arrhenius law by measuring the activities at different temperatures. The value of $E_{\mathrm{a}}$ was obtained via nonlinear regression of the linearized Arrhenius equation to the experimental data.

\subsection{GOS production}

GOSs formation kinetics with immobilized enzyme on MAGPANI was studied and compared with free enzyme. The lactose solution was prepared by dissolving lactose in citrate-phosphate buffer solution $\mathrm{pH}$ 4.5. Samples were taken at appropriate time intervals and analyzed for sugar content by HPLC. The reaction kinetics was studied at six different initial lactose concentrations $(50,100,200,300,400$ and $500 \mathrm{~g} / \mathrm{L})$ and four different temperatures $\left(30,40,50\right.$, and $\left.60^{\circ} \mathrm{C}\right)$. GOS yield was determination was based on the actual amount of consumed lactose (corresponding to the difference between initial lactose concentration and the lactose concentration at the corresponding reaction time). GOS yield value was obtaining by dividing the total amount $(\mathrm{g})$ of produced GOS by the amount of consumed lactose and multiplying by 100 .

All the experiments were done during $24 \mathrm{~h}$ in $15 \mathrm{~mL}$ centrifuge tubes containing $10 \mathrm{~mL}$ of citrate-phosphate buffer $\mathrm{pH} 4.5$ solution with the selected lactose concentration (between 50 and $500 \mathrm{~g} / \mathrm{L}$ ) and $100 \mathrm{mg}$ of support corresponding to an enzyme amount of $20.4 \mathrm{mg}$.

\subsection{Reuse of the immobilized enzyme}

The effect of enzymatic magnetic preparation reuse on its activity was evaluated by doing 10 cycles. Each cycle comprised 20 min of reaction for the activity determination according to Section 2.3, 40 min of washing 10 times the enzymatic magnetic preparation with $20 \mathrm{mM}$ citrate-phosphate buffer, $\mathrm{pH} 4.5$, totalizing $1 \mathrm{~h}$ of duration.

\subsection{HPLC analysis}

Determination of the concentration of all sugars present in the assay solution (GOSs, lactose, glucose, and galactose) was done by HPLC. An HPLC (Jasco AS-2057 Plus), employing a MetaCarb 87H at $60{ }^{\circ} \mathrm{C}$, a refractive index detector (Jasco RI-2031 Plus) and a mobile 
phase $0.001 \mathrm{~N} \mathrm{H}_{2} \mathrm{SO}_{4}$ at a flow rate of $0.5 \mathrm{~mL} \mathrm{~min}^{-1}$ (Jasco PU-2080 Plus) was used. The concentration (w/v) of these sugars (e.g., lactose, glucose, galactose, and oligosaccharides including tri-, and tetra-saccharides) is proportional to their peak areas. Thus, normalized sugar concentrations as weight percentages of total sugars or initial lactose were determined from peak areas and are reported in this work. It should be noted that the accuracy of this approximation was verified by checking the sugars mass balance.

\subsection{Support characterization}

The X-ray diffraction patterns of the samples were collected on a Philips-PW1710 diffractometer with $\mathrm{CuK} \alpha$ radiation $(\lambda=1.54056 \AA)$. Elemental analysis of dried samples was determined by a LECO Elemental Analyser CHNS 932 and Unicam 929 AA spectrophotometer (USA) at $1000^{\circ} \mathrm{C}$ and sulphamethazine with standard. For SEM, the samples were mounted on stubs, coated with gold, examined in a Leica Cambridge S360 scanning electronic microscope and SEM micrographs were taken. Infrared spectra were recorded on an ABB FTLA2000 spectrometer in the range of $500-4000 \mathrm{~cm}^{-1}$ using $\mathrm{KBr}$ pellets. Thermal analyses TGA and DSC of MAG and MAG-PANI were done using a TGA-50 and a DSC-50 both from Shimadzu (Izasa, S.A., Portugal). Acquisition of the results was done by TA-50WS software (version 1.14). Samples were weighed (10 $\mathrm{mg}$; the exact mass was recorded) into aluminium pans (Izasa, S.A., Portugal) and heated over the temperature range of $25-500^{\circ} \mathrm{C}$, at a scanning rate of $5{ }^{\circ} \mathrm{C} / \mathrm{min}$, under $20 \mathrm{~mL} / \mathrm{min}$ nitrogen flow. The magnetic properties of the sample MAG-PANI were investigated by measuring its hysteresis loop at room temperature using an Oxford instrument Vibrating Sample Magnetometer and the thermomagnetization from room temperature to $1000^{\circ} \mathrm{K}$ using a Cahn 2000 Curie-Faraday balance.

\section{Results and discussion}

\subsection{Effects of lactose concentration on reaction kinetics by free and immobilized enzyme}

Magnetic particles were obtained by co-precipitation of $\mathrm{Fe}^{2+}$ and $\mathrm{Fe}^{3+}$ and afterwards coated with PANI. The enzyme was then covalently linked to the PANI via glutaraldehyde.

The amount of $\beta$-galactosidase immobilized onto MAG-PANI was estimated as $2.04 \mathrm{mg} / \mathrm{g}$ support. Although this value is smaller than the $9.87 \mathrm{mg} / \mathrm{g}$ support reported by Bayramoglu et al. [13] for magnetic poly(GMA-MMA) beads, it is higher than most of the values reported in the literature: $0.35 \mathrm{mg} / \mathrm{g}$ support [23] and $0.40 \mathrm{mg} / \mathrm{g}$ support [24].

The $\beta$-galactosidase activity values for both free and immobilized enzyme are presented in Table 1 . The obtained results showed that for the lactose concentrations up to $100 \mathrm{~g} / \mathrm{L}$, no differences were observed in the enzyme specific activity between free and immobilized forms (100\% of specific activity retention). However, for higher lactose concentrations, the initial specific reaction rate of

\section{Table 1}

$\beta$-Galactosidase activity values for both free and immobilized enzyme on MAG-PANI acting on different lactose concentrations.

\begin{tabular}{rll}
\hline \multirow{2}{*}{ Lactose $(\mathrm{g} / \mathrm{L})$} & \multicolumn{2}{l}{ Specific activity (U/mg of protein) } \\
\cline { 2 - 3 } & Free & Immobilized \\
\hline 50 & 36.2 & 35.8 \\
100 & 50.9 & 48.5 \\
200 & 68.5 & 62 \\
300 & 79.2 & 72.4 \\
400 & 84 & 74.6 \\
500 & 94.8 & 74.2 \\
\hline
\end{tabular}
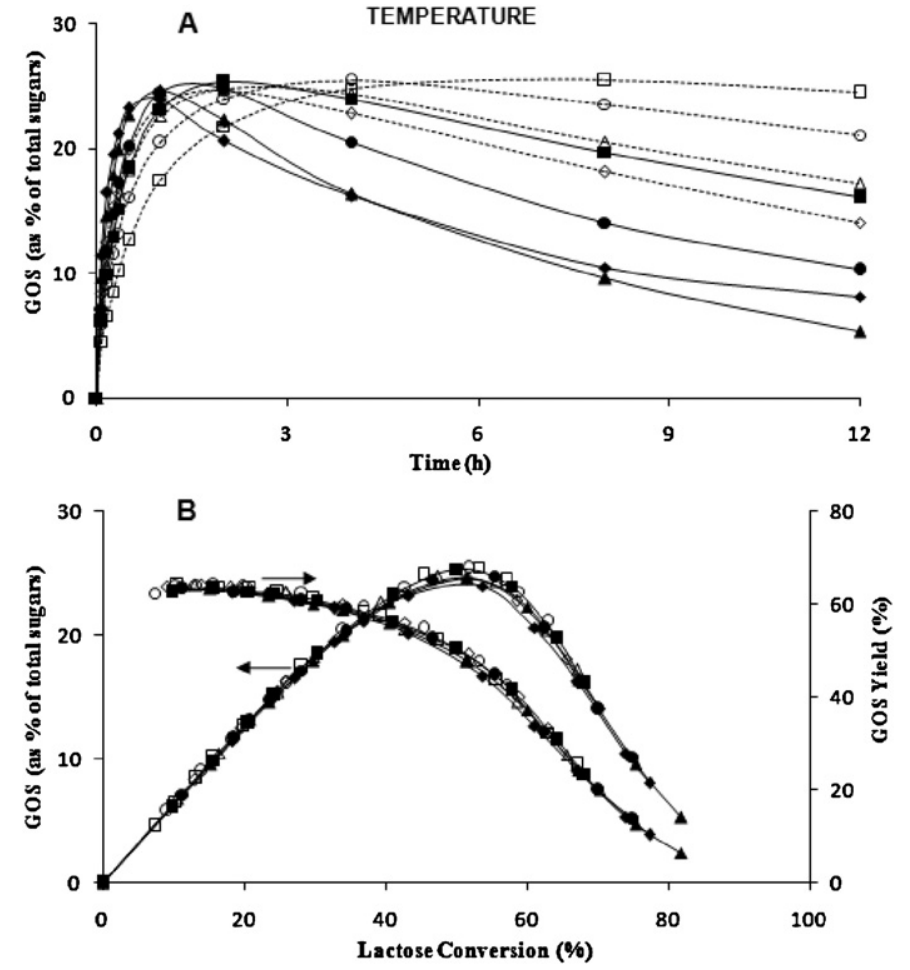

Fig. 1. Effect of temperature on the GOS production during the hydrolysis of $40 \%$ (w/v) lactose catalyzed by the free (open symbols) and immobilized (closed symbols) A. oryzae $\beta$-galactosidase on MAG-PANI. (A) Time course of GOS production, and (B) GOSs production versus lactose consumption. The temperatures were $30^{\circ} \mathrm{C}(\boldsymbol{\square})$; $40^{\circ} \mathrm{C}(\bullet) ; 50{ }^{\circ} \mathrm{C}(\boldsymbol{\Delta}) ; 60^{\circ} \mathrm{C}(\bullet)$.

the immobilized form was affected by increasing lactose concentrations, probably, caused by mass transfer limitations associated with the increase in both density and viscosity of the substrate solution.

The temperature effect was evaluated in the temperature range of $30-60^{\circ} \mathrm{C}$ and the results are displayed in Fig. 1. The GOS production by either the free or the immobilized enzyme increased up to a maximum value followed by a decrease caused by their hydrolysis (Fig. 1A). This GOS reduction is more accentuated as higher the temperature achieves. However, this same result plotted as GOS production versus lactose conversion demonstrated that the GOS production was almost unchanged for both the free and immobilized enzyme preparations at the investigated temperature range (Fig. 1B). Similar results for $\beta$-galactosidase from $A$. oryzae immobilized on Cotton Cloth were reported by Albayrak and Yang [24].

In what concerns the dependence of the reactions kinetics on the temperature, no effect of the immobilization procedure was observed as the Activation Energy for both free and immobilized forms was similar, for the immobilized form the obtained value was $16.7 \pm 1.4 \mathrm{KJ} / \mathrm{mol}$ and for the free form $16.4 \pm 1.4 \mathrm{KJ} / \mathrm{mol}$.

\subsection{Effects of lactose concentration on GOS production yield by free and immobilized enzyme}

Fig. 2A shows that the time course of GOS (tri- and tetrasaccharides) production by both the free and immobilized enzyme at $50 \%$ of initial lactose concentration increases up to a maximum value and decrease afterwards (GOS hydrolysis). The immobilized form presented slightly higher GOS production rate compared to the free one. This higher activity is also reflected at the GOS hydrolysis stage (the decline of the curve). However, the maximum GOS productions are the same for both forms. Thus, the trisaccharide production in the reaction is higher (about $21 \%$ of total 

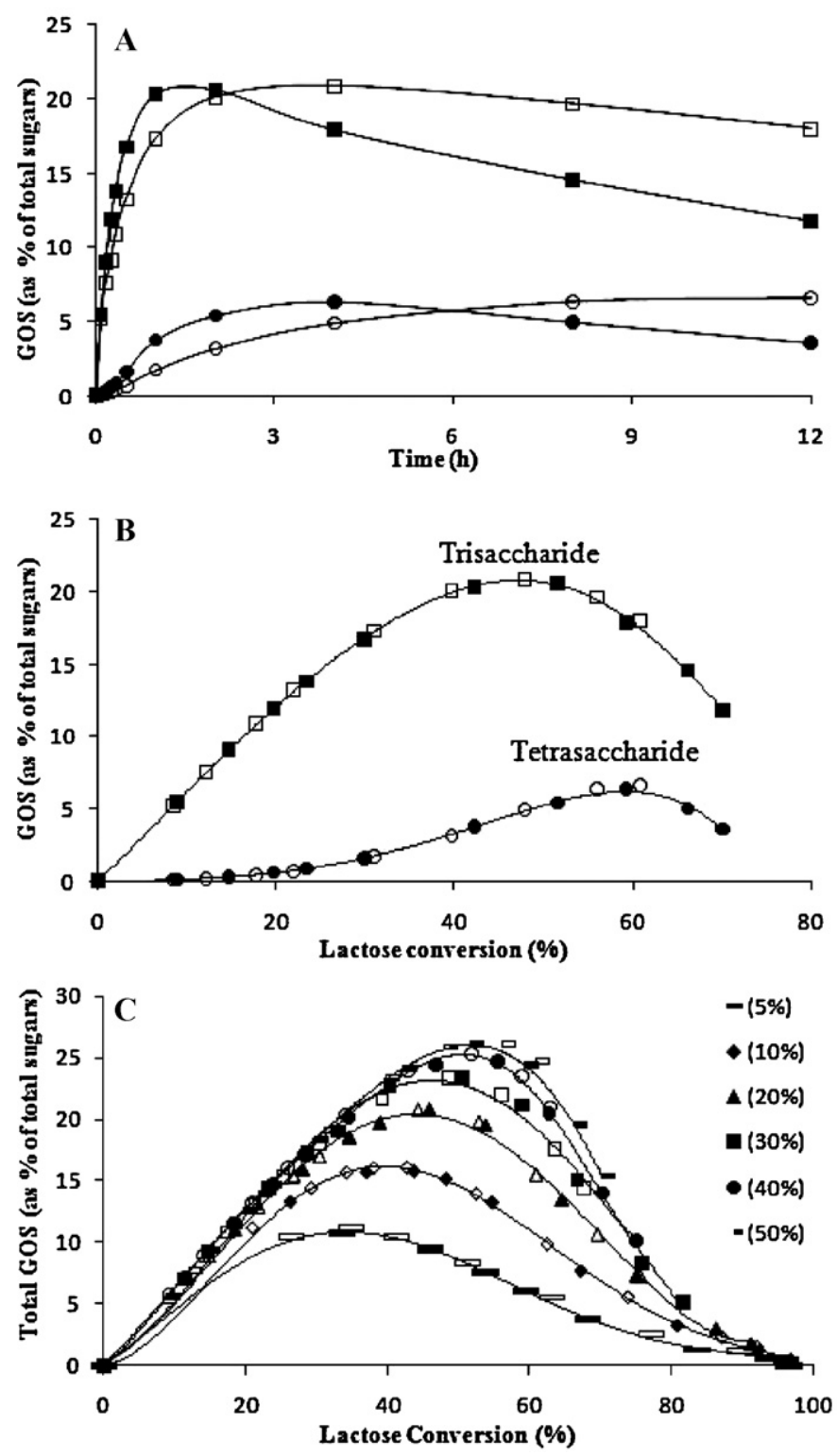

Fig. 2. (A) Time course of tri- $(\square)$ and tetra-saccharides $(\bigcirc)$ formation by free (open) and immobilized on MAG-PANI (closed) A. oryzae $\beta$-galactosidase acting on $50 \%$ initial lactose concentration (w/v) at $\mathrm{pH} 4.5$ and $40^{\circ} \mathrm{C}$; and (B) related to lactose conversion and (C) total GOS production for different initial lactose concentration.

sugars for $50 \%, w / v$, of lactose) than the tetrasacharide (about $6 \%$ of total sugars for $50 \%, w / v$, lactose). The proportions of tri- and tetra-oligosaccharides (at 52\% lactose conversion), during lactose hydrolysis with $50 \%$ initial lactose concentration at $40^{\circ} \mathrm{C}$, were approximately $76 \%$ and $24 \%$ of total GOS formed, respectively. Albayrak and Yang, working with $\beta$-galactosidase from A. oryzae immobilized on cotton cloth in the same condition, obtained similar results [25]. Plotting the data of Fig. $2 \mathrm{~A}$ in terms of tri- and tetra-saccharides produced by percent of lactose conversion one can observe that there is no difference between the free and the immobilized enzyme performance (Fig. 2B).

Identical experiments were performed for the other lactose concentrations (5-40\%, w/v) and the total mass of produced GOS (expressed as percent of total sugars) plotted against the percent of hydrolyzed lactose (Fig. 2C). This result shows that GOS production increased with increasing lactose concentration. However, for each lactose concentration the GOS production decreased after a certain degree of lactose conversion. This can be attributed to a preferential

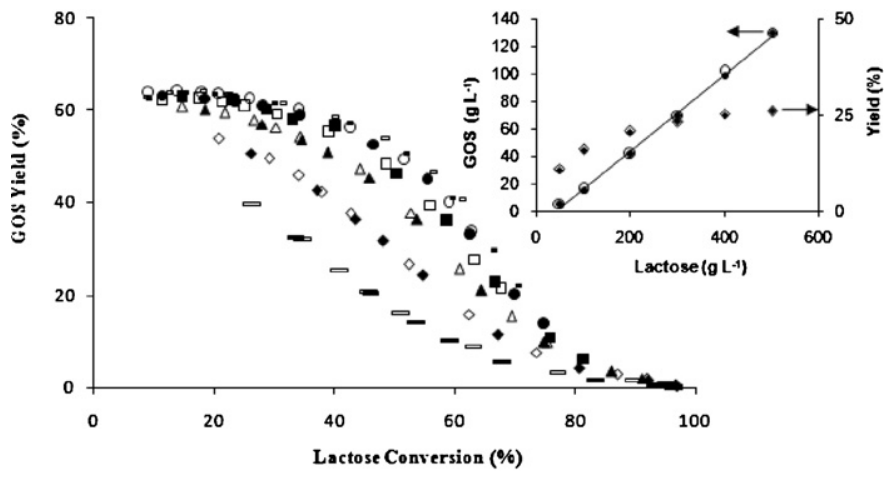

Fig. 3. GOS yield versus percent of lactose conversion by free (open symbols) and immobilized on MAG-PANI (closed symbols) A. oryzae $\beta$-galactosidase. The insert presents the same relationship expressed in terms of total GOS $(\mathrm{g} / \mathrm{L})$ and maximum GOS yield. The initial concentrations of lactose were 5\% (-); $10 \%(\bullet) ; 20 \%(\boldsymbol{\Delta}) ; 30 \%$ (ם); 40\% (•) and 50\% (ם) (w/v).

hydrolysis reaction (formation of glucose and galactose) instead of GOS synthesis. As the initial lactose concentration increased from $5 \%$ to $50 \%$, the maximum GOS content in the product increased from $11.2 \%$ (at $35 \%$ conversion) to $26.1 \%$ (at $56 \%$ conversion) for the free enzyme and from $10.8 \%$ (at $33 \%$ conversion) to $26.0 \%$ (at $52 \%$ conversion) for the immobilized enzyme. The maximum amount of tri-, tetra-saccharides and total GOS obtained for the immobilized enzyme were $103.2 \mathrm{~g} \mathrm{~L}^{-1}, 31.9 \mathrm{~g} \mathrm{~L}^{-1}$ and $130.2 \mathrm{gL}^{-1}$ for a lactose conversion of about $52 \%, 59 \%$, and $52 \%$, respectively, in $500 \mathrm{~g} \mathrm{~L}^{-1}$ of lactose. For the free enzyme, $104.5 \mathrm{~g} \mathrm{~L}^{-1}, 33.2 \mathrm{~g} \mathrm{~L}^{-1}$ and $130.3 \mathrm{~g} \mathrm{~L}^{-1}$ were obtained for about $48 \%, 61 \%$ and $56 \%$ lactose conversion, respectively in $500 \mathrm{~g} \mathrm{~L}^{-1}$ of lactose. These results suggest that enzyme immobilization on MAG-PANI does not impose any limitation on the extent of the reaction of GOS formation from lactose. Similar results were obtained with $\beta$-galactosidase from $A$. oryzae immobilized on cotton cloth [25]. Thus, the GOS formation ability of the enzyme was not affected by the immobilization of the enzyme onto MAG-PANI. The good performance of the immobilized enzyme derivative may have also likely been due to the glycosilated nature of the enzyme associated to the fact that a polymeric coated support was utilized, and this consortium seems to have prevented any reaction extent related problems. This is in clear agreement with results by Betancor et al. [26]. These authors also reported immobilized enzyme inactivation by bubbles. However, they mecanically stirred the reactor at $1200 \mathrm{rpm}$ whereas the speed of $20 \mathrm{rpm}$ was used in this work.

GOS yields, based on the actual amount of lactose reacted, during lactose hydrolysis catalyzed by the free and the immobilized $\beta$-galactosidase on MAG-PANI are showed in Fig. 3. The maximum GOS yield increased with the initial lactose concentration by the catalysis of both enzyme preparations. This maximal values ranged from $39.5 \%(5 \%, \mathrm{w} / \mathrm{v}$, lactose) to $64.1 \%$ (higher lactose concentrations) for the free enzyme and from $32.2 \%(5 \%, \mathrm{w} / \mathrm{v}$, lactose) to $63.5 \%$ (higher lactose concentrations) for the immobilized one. It was generally observed that the hydrolysis and transgalactosylation reactions occurred simultaneously. What dominates the product profile of the reaction is largely dependent on lactose concentration. The hydrolysis reaction dominates at low lactose concentration while GOS formation dominates at high lactose concentrations. $\beta$-Galactosyl groups should have a higher probability of attaching to lactose than water at increasing lactose concentrations [27]. The insert of Fig. 3 presents these same data under other perspective, namely, increases in lactose concentration led to increases in GOS production. However, in terms of GOS yield, it was observed an increase until 30\% of lactose and for higher the yield was almost constant at $23.3-26 \%$ for both free and immobilized enzyme. Park et al. observed the same behaviour for high lactose 
concentration with a thermostable $\beta$-galactosidase from Sulfolobus solfataricus [28].

\subsection{Reuse of the immobilized enzyme}

Having confirmed the dependence of the reaction kinetics on the temperature, the reuse of the immobilized preparation was evaluated for 10 reuse cycles, at $25^{\circ} \mathrm{C}$ and initial lactose concentration of $20 \%(\mathrm{w} / \mathrm{v})$. At the end of the 10 th cycle, the enzymatic derivative retained approximately $85 \%$ of its initial activity (data not shown). This performance of the MAG-PANI $\beta$-galactosidase derivative would be an additional advantage besides that from its easy of separation from the reaction medium by a magnetic field.

\subsection{Support characterization}

Fig. 4 shows the results of X-ray diffraction analysis for the MAGPANI support. Patterns of iron oxides of the Joint Committee on Powder Diffraction Standards - International Centre for Diffraction Data (JCPDS-ICDD) database were included for comparison. Both magnetite and maghemite have a spinel structure. Their lines are close and it is difficult to distinguish them from one another by X-ray diffraction pattern. The X-ray diffraction data expressed in A compared with those for magnetite according to the JCPDS database (bracketes) at the crystalline planes $(h / k) 220 ; 311 ; 400$; 42 2; 511 and 440 are, respectively, 2.962 (2.967); 2.516 (2.532); 2.090 (2.099); 1.705 (1.715); 1.609 (1.616) and 1.478 (1.485). From this result one can deduce that magnetite constituted the dominant phase in the MAG-PANI, although trace amounts of maghemite may probably have been formed as contaminants during the synthesis process.

Fig. 5 shows the scanning electron microscopy (SEM) analysis of MAG and MAG-PANI particles. MAG particles were obtained of the co-precipitated with $\mathrm{Fe}^{2+}$ and $\mathrm{Fe}^{3+}$ and MAG-PANI particles were obtained with PANI coating on MAG. The SEM images indicate rhombohedra particles, the coating with PANI does not alter the MAG structure and MAG-PANI presents a similar format to MAG.

Elemental analysis was done to determine the composition of each fraction: (1) MAG; (2) MAG-PANI and (3) MAG-PANI activated with glutaraldehyde plus protein immobilized (Table 2 ). This result shows that MAG alone did not have any analyzed element $(\mathrm{N}, \mathrm{C}$, $\mathrm{H}$ and $\mathrm{S}$ ), whereas they are as expected present in the MAG-PANI composite, except sulfur which appears in the composite activated with glutaraldehyde plus immobilized protein.

Infrared spectra of MAG and MAG-PANI are shown in Fig. 6 depicting considerable different vibrations. The characteristic

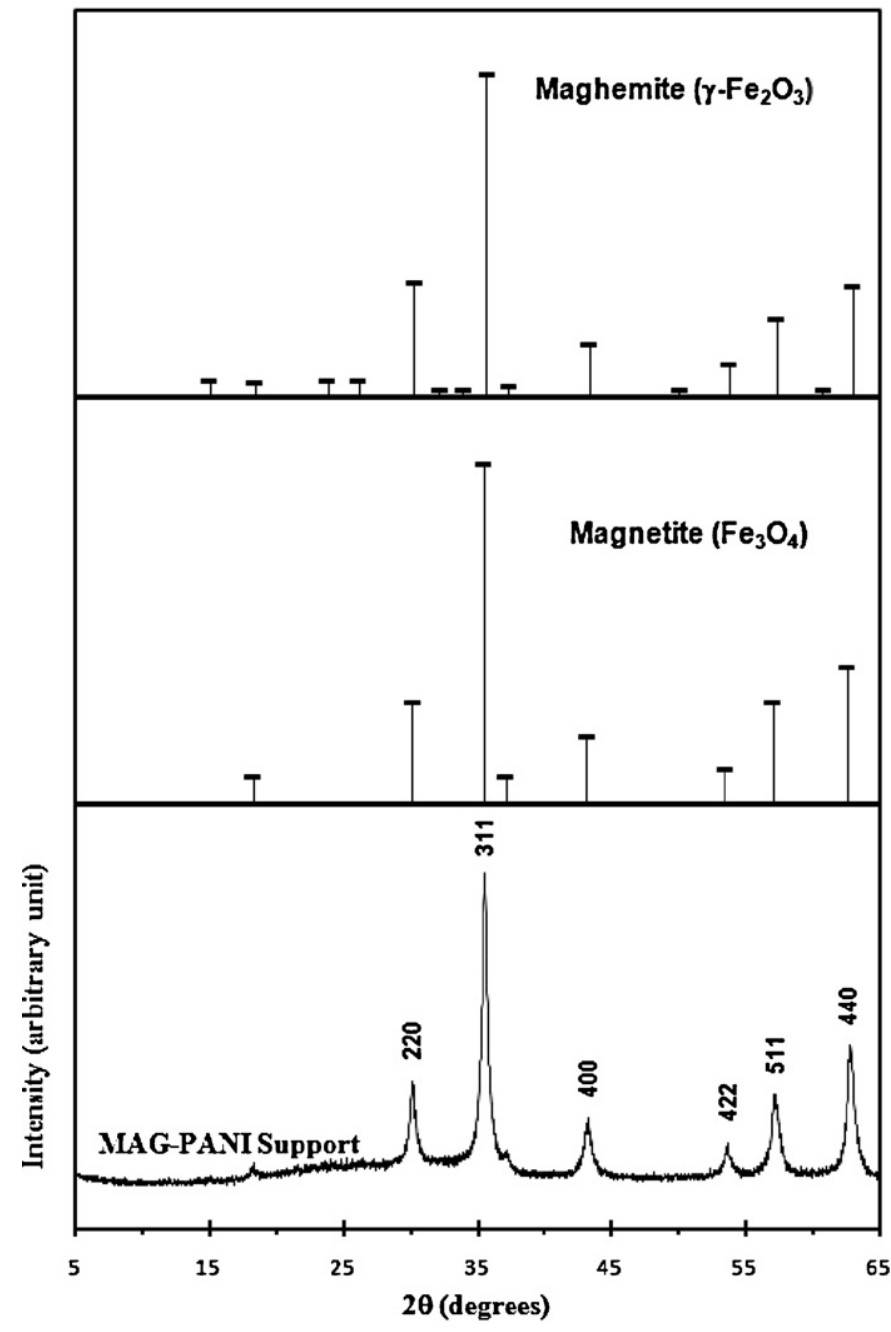

Fig. 4. X-ray diffraction patterns of MAG-PANI, magnetite oxide and maghemite oxide (both magnetite and maghemite oxides patterns were obtained from the JCPDS-ICDD database).

peaks of MAG-PANI occur at 1588, 1504, 1384, 1306, 1145 and $828 \mathrm{~cm}^{-1}$. Jiang et al. obtained similar results to PANI/magnetic ferrite nanocomposites [29]. This result seems to be a consistent evidence of PANI coating on MAG.

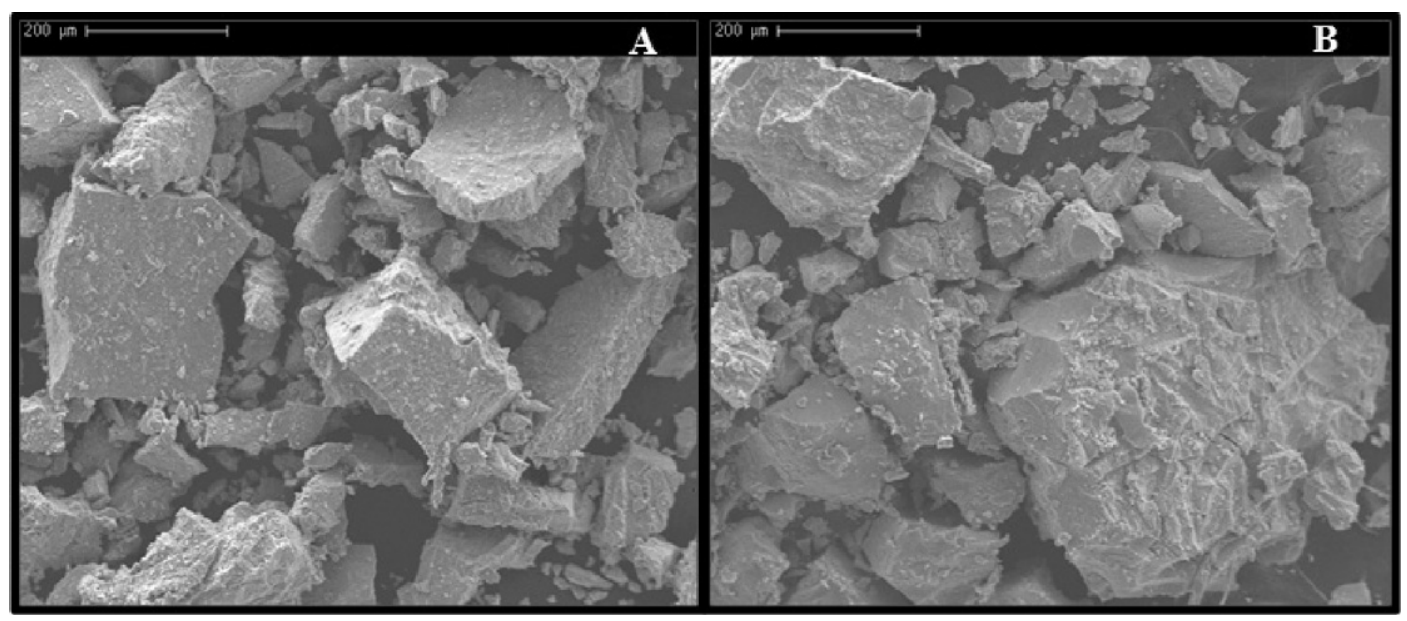

Fig. 5. Ultrastructural image of MAG (A) and MAG-PANI (B), obtained by scanning electron microscopy. 
Table 2

Elemental analysis to determine the composition of each fraction of magnetic particles (MAG free, MAG with PANI and MAG with PANI activated with glutaraldehyde plus $\beta$-galactosidase immobilized).

\begin{tabular}{lllll}
\hline \multirow{2}{*}{ Fraction of magnetic particles } & \multicolumn{4}{l}{ Element (\%) } \\
\cline { 2 - 5 } & Nitrogen & Carbon & Hydrogen & Sulfur \\
\hline MAG & 0 & 0 & 0 & 0 \\
MAG + PANI & 0.951 & 5.657 & 0.378 & 0 \\
MAG + PANI + $\beta$-galactosidase & 0.834 & 5.397 & 0.415 & 0.316 \\
\hline
\end{tabular}

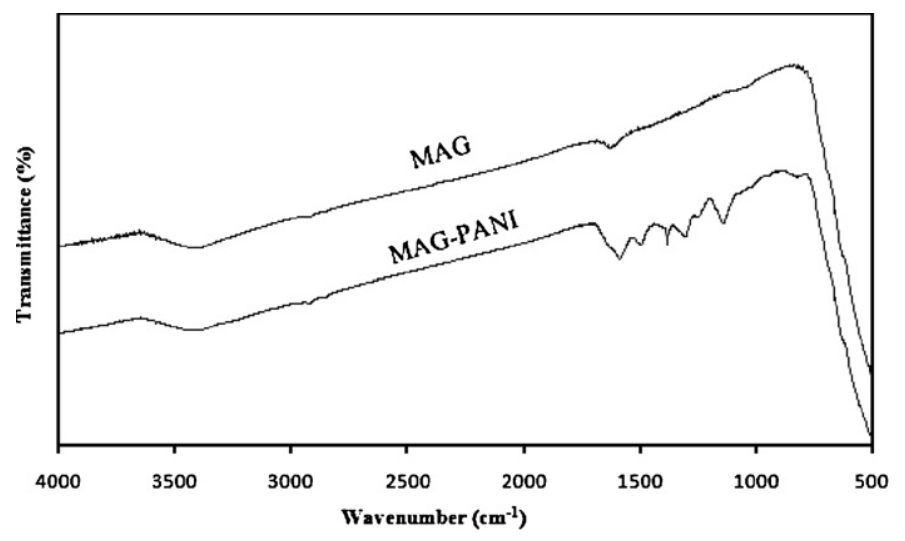

Fig. 6. Infrared absorption spectra of the MAG and MAG-PANI.

The MAG-PANI presented a good magnetic response, being easily attracted by a magnetic separator as is shown in Fig. 7. In order to study the MAG-PANI magnetic behaviour magnetization measurements were performed by analyzing its hysteresis loop at room temperature. As can be observed in Fig. 8 the magnetization of the MAG-PANI exhibited a clear hysteretic behaviour. The saturation magnetization was measured to be approximately $60 \mathrm{emu} / \mathrm{g}$ (see Fig. 8), this value being in fair well agreement with the value found for magnetite [30].

Another important parameter analyzed was the curve of the magnetic moment against temperature (Fig. 9) that shows the MAG-PANI sample has two phases possibly magnetite (dominant) and maghemite. The transformation of magnetite to maghemite can occur in the range of $650-750^{\circ} \mathrm{K}$ depending of the specific environment conditions and size of the particles (see Fig. 9A) [31]. In addition, an irreversible transformation to hematite due

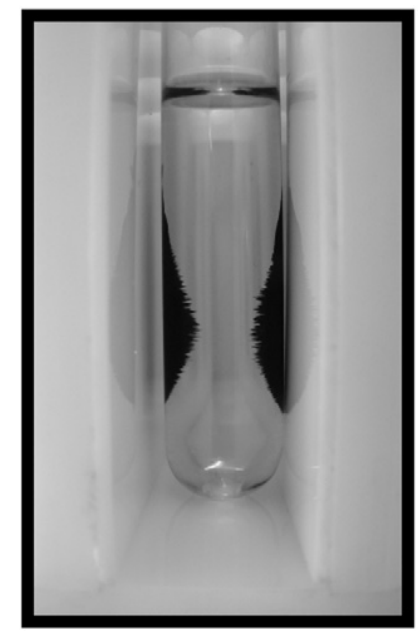

Fig. 7. Induced MAG-PANI separation from the reaction medium by the application of a magnetic field. MAG-PANI support is displaced towards the tube walls.

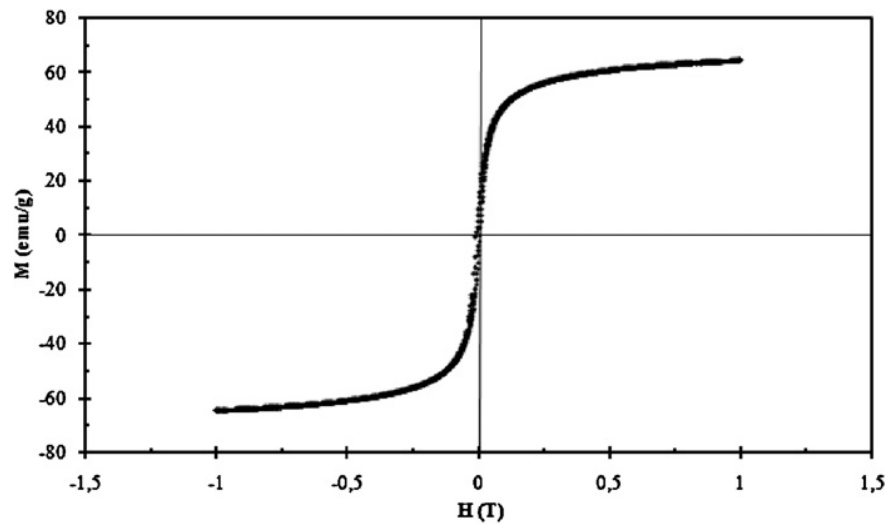

Fig. 8. Experimental values for the hysteresis loop of the MAG-PANI at room temperature, confirming the existence of a saturation magnetization value.

to oxidation occurs above $830^{\circ} \mathrm{K}$ near the transition temperature $\mathrm{Tc}=850^{\circ} \mathrm{K}$ as can be seen in Fig. 9B [31-33].

Fig. 10 shows the results from the thermal analysis relative to MAG and MAG-PANI. The TGA curves exhibit three steps of mass loss; these are more pronounced for MAG-PANI (Fig. 10B). The two endothermic peaks (Fig. $10 \mathrm{~A}$ ) up to $170^{\circ} \mathrm{C}$ correspond to the initial removal of moisture (Fig. 10B) and can possibly correspond to free and bound water. Above this temperature, exothermic peaks may be associated to the thermal degradation of PANI [34,35]. This is most visible within the range of $200-400^{\circ} \mathrm{C}$ for the DSC curve and within $150-330^{\circ} \mathrm{C}$ for the TGA curve (Fig. $10 \mathrm{~A}$ and B; MAGPANI). In this work a nitrogen flux was used during the calorimetric assays. The conversion of magnetite to hematite (Fig. 10A; MAG),
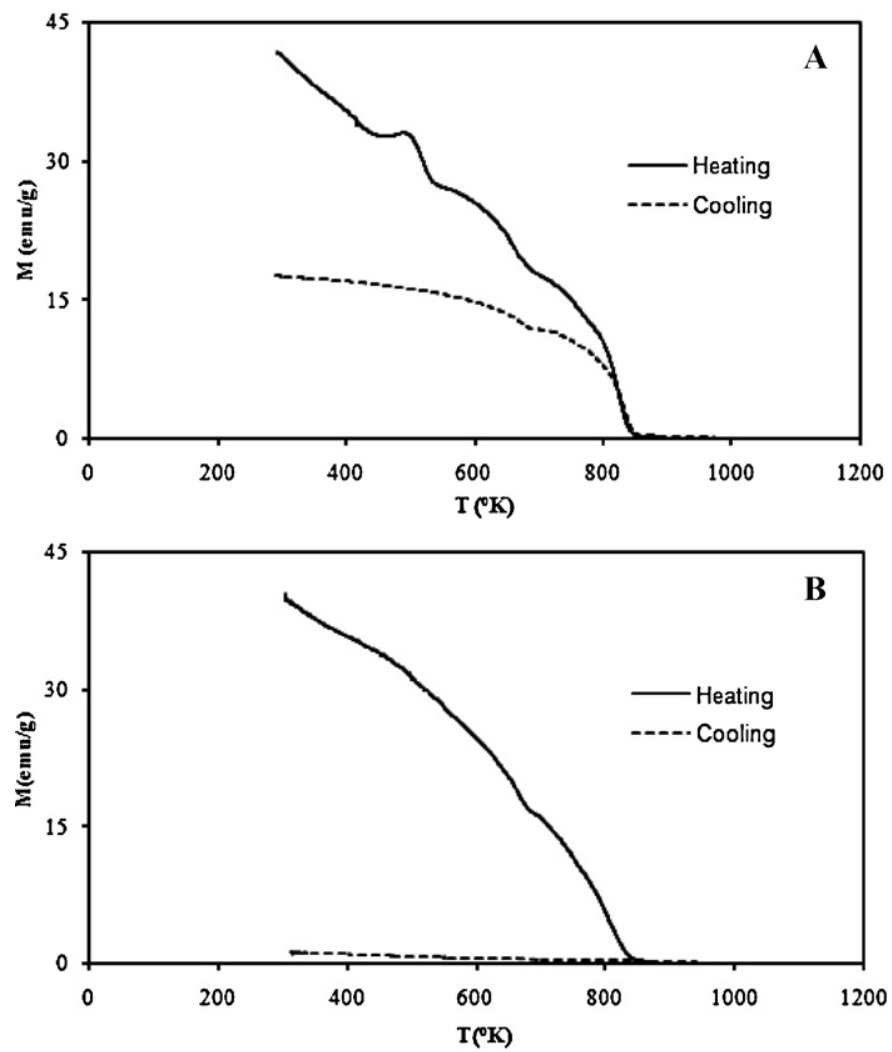

Fig. 9. Experimental vales for the curve of the magnetic moment (M) against temperature (T) of MAG-PANI from room temperature to $1000^{\circ} \mathrm{K}$, for heating and cooling. Data on A corresponds to the first heating/cooling cycle and on B to the second heating/cooling cycle. 

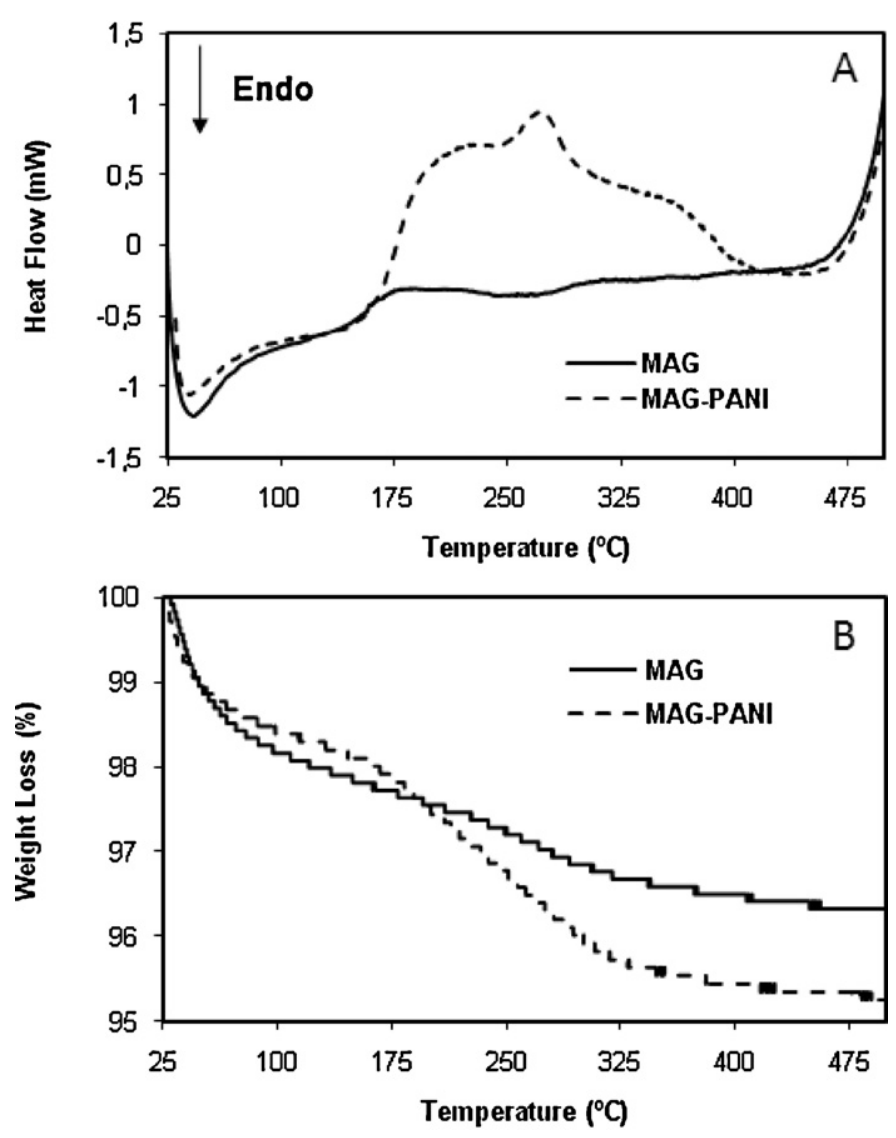

Fig. 10. Thermal analysis data for MAG and MAG-PANI obtained by DSC heat flow (A) and thermogravimetry curves (B).

detectable at $225^{\circ} \mathrm{C}$ [36], can therefore be excluded as oxygen is required to complete the reaction.

\section{Conclusion}

According to the results above presented a catalytically active magnetic derivative of $A$. orizae $\beta$-galactosidase was synthesized. Firstly, magnetic particles were obtained by coprecipitation of $\mathrm{Fe}^{2+}$ and $\mathrm{Fe}^{3+}$ and coated with PANI afterwards. This magnetic preparation was capable to convert lactose into galactose and glucose and to produce tri and tetra-galactosides (transgalactosylation) as well. This performance did not differ from that for the free and immobilized enzyme. The tri and tetra-saccharides production by both free and immobilized enzyme was not affected by temperature from $30^{\circ} \mathrm{C}$ to $60^{\circ} \mathrm{C}$. The analysis of this $\beta$-galactosidase-magnetic composite revealed: (1) rhombohedra particles showing good magnetic response; (2) the elemental analysis and infrared spectra provided evidences for the PANI coating and the protein immobilization; and (3) X-ray diffraction, magnetization measurements at $25^{\circ} \mathrm{C}$, curve of the magnetic moment against temperature and thermal analysis were in agreement with magnetite composition predominantly. Furthermore, this magnetic enzymatic derivative presented the following advantages: simple synthesis using low cost reagents, similar catalytic properties of the soluble enzyme and easy removal from the reaction mixture by a magnetic field and reuse.

\section{Acknowledgments}

David F. M. Neri gratefully acknowledges support by the Programme Alßan, the European Union Programme of High Level Scholarships for Latin America (Scholarship no. E05D057787BR) and by the Foundation for the Support of Science and Technology of the Pernambuco State - FACEPE (APQ-0121-2.08/09). Luiz B. Carvalho Jr. is recipient of a scholarship of the Brazilian National Research Council (CNPq).

\section{References}

[1] P.S. Panesar, R. Panesar, R.S. Singh, J.F. Kennedy, H. Kumar, Journal of Chemical Technology \& Biotechnology 81 (2006) 530.

[2] R. Gaur, H. Pant, R. Jain, S.K. Khare, Food Chemistry 97 (2006) 426.

[3] C.S. Kim, E.S. Ji, D.K. Oh, Biochemical and Biophysical Research Communications 316 (2004) 738.

[4] R.R. Mahoney, Food Chemistry 63 (1998) 147.

[5] D.F.M. Neri, V. Balcão, R. Costa, I. Rocha, E. Ferreira, D. Torres, L. Rodrigues, L. Carvalho Jr., J.A.C. Teixeira, Food Chemistry 115 (2009) 92.

[6] T. Kuroiwa, Y. Noguchi, M. Nakajima, S. Sato, S. Mukataka, S. Ichikawa, Process Biochemistry 43 (2008) 62.

[7] M.C.B. Pimentel, A.B.F. Leāo, E.H.M. Melo, W.M. Ledingham, J.L. Lima-Filho, M. Sivewright, J.F. Kennedy, Artificial Cells, Blood Substitutes and Biotechnology 35 (2007) 221

[8] G. Bayramoglu, M.Y. Arıca, Journal of Molecular Catalysis B: Enzymatic 55 (2008) 76.

[9] G. Bayramoglu, S. Kiralp, M. Yilmaz, L. Toppare, M.Y. Arıca, Biochemical Engineering Journal 38 (2008) 180.

[10] L.M. Bruno, J.S. Coelho, E.H.M. Melo, J.L. Lima-Filho, World Journal of Microbiology and Biotechnology 21 (2005) 189.

[11] B.R. Pieters, G. Bardeletti, Enzyme and Microbial Technology 14 (1992) 361

[12] R.F. Dekker, Applied Biochemistry and Biotechnology 22 (1989) 289.

[13] G. Bayramoglu, Y. Tunali, M.Y. Arica, Catalysis Communications 8 (2007) 1094.

[14] D.F.M. Neri, V.M. Balcão, M.G. Carneiro-da-Cunha, L.B. Carvalho Jr., J.A. Teixeira, Catalysis Communications 9 (2008) 2334.

[15] J. Huang, Pure and Applied Chemistry 78 (2006) 15.

[16] G.B. Oliveira, J.L. Lima-Filho, M.E.C. Chaves, W.M. Azevedo, L.B. Carvalho Jr. Reactive Functional Polymers 68 (2008) 27.

[17] K.D. Seo, S.D. Oh, S.H.Choi, S.H. Oh, J.C. Woo, S.H. Kim, Key Engineering Materials 342 (2007) 869

[18] R.A.L. Coêlho, G.M.P. Santos, P.H.S. Azevêdo, G.A. Jaques, W.M. Azevedo, L.B. Carvalho Jr., Journal of Biomedical Materials Research 56 (2001) 257.

[19] D.F.M. Neri, V. Balcão, F.O.Q. Dourado, J.M.B. Oliveira, L.B. Carvalho Jr., J.A.C. Teixeira, Reactive and Functional Polymers 69 (2009) 246.

[20] B.C.C. Pessela, L. Betancor, F. Lopez-Gallego, R. Torres, G.M. Dellamora-Ortiz, N. Alonso-Morales, M. Fuentes, R. Fernández-Lafuente, J.M. Guisán, C. Mateo, Enzyme and Microbial Technology 37 (2005) 295.

[21] L. Wilson, A. Illanes, O. Abian, B.C.C. Pessela, R. Fernández-Lafuente, J.M. Guisán, Biomacromolecules 5 (2004) 852.

[22] P.K. Smith, R.I. Khron, G.F. Hermanson, A.K. Mallia, F.H. Gartner, M.D. Provenzano, E.K. Fujimoto, N.M. Goeke, B.J. Olson, D.C. Klent, Biochemistry 150 (1985) 76.

[23] M. Ladero, A. Santos, F. García-Ochoa, Enzyme and Microbial Technology 27 (2000) 583.

[24] B.C.C. Pessela, G. Dellamora-Ortiz, L. Betancor, M. Fuentes, J.M. Guisán, R Fernandez-Lafuente, Enzyme and Microbial Technology 40 (2007) 310.

[25] N. Albayrak, S.T. Yang, Biotechnology and Bioengineering 77 (2002) 8

[26] L. Betancor, M. Fuentes, G. Dellamora-Ortiz, F. López-Gallego, A. Hidalgo, N. Alonso-Morales, C. Mateo, J.M. Guisán, R. Fernández-Lafuente, Journal of Molecular Catalysis B: Enzymatic 32 (2005) 97.

[27] K. Iwasaki, M. Nakajima, S. Nakao, Process Biochemistry 31 (1996) 69

[28] H.Y. Park, H.J. Kim, J.K. Lee, D. Kim, D.K. Oh, World Journal of Microbiology and Biotechnology 24 (2007) 1553.

[29] J. Jiang, L. Li, M. Zhu, Reactive and Functional Polymers 68 (2008) 57.

[30] R.J. Harrison, A. Putnis, American Mineralogist 80 (1995) 213.

[31] Lauer Jr., H.V., Ming, D.W., Golden, D.C., Lin, I.C. (2001) http://www.lpi.usra.edu/meetings/lpsc2001/pdf/2071.pdf.

[32] R. Janot, D. Guerard, Journal of Alloys and Compunds 333 (2002) 302.

[33] G.M. Costa, E. Grave, R.E. Vandenberghe, Hyperfine Interactions 117 (1998) 207.

[34] R. Fryczkowski, C. Slusarczyk, J. Fabia, Synthetic Metals 156 (2006) 310.

[35] C. Basavaraja, R. Pierson, T.K. Vishnuvardhan, H. Do Sun, European Polymer Journal 4 (2008) 1556.

[36] Lauer, H., Ming, D., Golden, D. (2003) Abstract: 1341. 